\title{
Public access to protocols of contemporary cancer randomized clinical trials
}

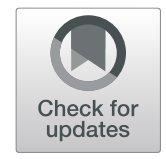

Christopher Babu', Loren Mell ${ }^{2}$, Nancy Lee ${ }^{3}$ and Kaveh Zakeri ${ }^{3^{*}}$

\begin{abstract}
Access to randomized clinical trial (RCT) protocols is necessary for the interpretation and reproducibility of the study results, but protocol availability has been lacking. We determined the prevalence of protocol availability for all published cancer RCTs in January 2020. We found that only 36.1\% (48/133) of RCTs had an accessible protocol and only $11.3 \%$ of RCTs (15/133) had a publicly accessible protocol that was not behind a paywall. Only $18.0 \%$ (24/133) of RCTs were published in conjunction with the protocol on the journal website. In conclusion, few cancer RCTs have an accessible research protocol. Journals should require publication of RCT protocols along with manuscripts to improve research transparency.
\end{abstract}

Keywords: Protocols, Clinical trials, Access, Cancer

Randomized clinical trials (RCTs) are the gold standard for evaluating medical interventions, yet RCTs have been plagued by selective reporting and "spin" (i.e., misrepresentation of results) [1,2]. Access to RCT protocols can serve as a public safeguard against biased clinical trial design and reporting, but protocol transparency has generally been lacking $[3,4]$. Increasingly, some medical journals will publish standalone protocols for open access at the outset of a clinical trial [5]. However, protocol modifications are common, including changes to the eligibility, treatment, and primary endpoint [6], and thus, the final version of the amended protocol is needed for readers to fully interpret the scientific rigor and results of a study. Medical journals can play a critical role in improving the transparency of RCTs by requiring publication of all iterations of the protocol alongside trial manuscripts. While some high-impact medical journals require publication of protocols [7], less is known about the public availability of protocols for cancer RCTs published across the medical literature.

\footnotetext{
* Correspondence: zakerik@mskcc.org

${ }^{3}$ Department of Radiation Oncology, Memorial Sloan Kettering Cancer Center, New York, NY, USA

Full list of author information is available at the end of the article
}

\section{Methods}

Our primary aim was to determine the availability of research protocols in a contemporary cross-section of published cancer RCTs. We conducted a PubMed search of all published cancer RCTs in the month of January 2020. The search query (Additional file 1) yielded 1098 results that were assessed by two authors $(\mathrm{CB}, \mathrm{KZ})$ to determine if they were RCTs. For published RCTs that did not include a protocol in the online materials, we conducted an internet search including ClinicalTrials.gov, PubMed, and Google to determine whether a current or prior version of the protocol was available (Additional file 2). Only primary analyses of RCTs were included. Pilot RCTs and studies not written in English were excluded. Two-sided Mann-Whitney $U$ and chisquare tests were used to compare differences between groups and the analysis was conducted in $\mathrm{R}$.

\section{Results}

A total of 133 RCTs were included in the final analysis (Fig. 1). Within this cohort, the median study sample size was 128 and most studies investigated cancerdirected therapy $(40.6 \%)$ or supportive care interventions (45.9\%), such as symptom control, patient satisfaction, 


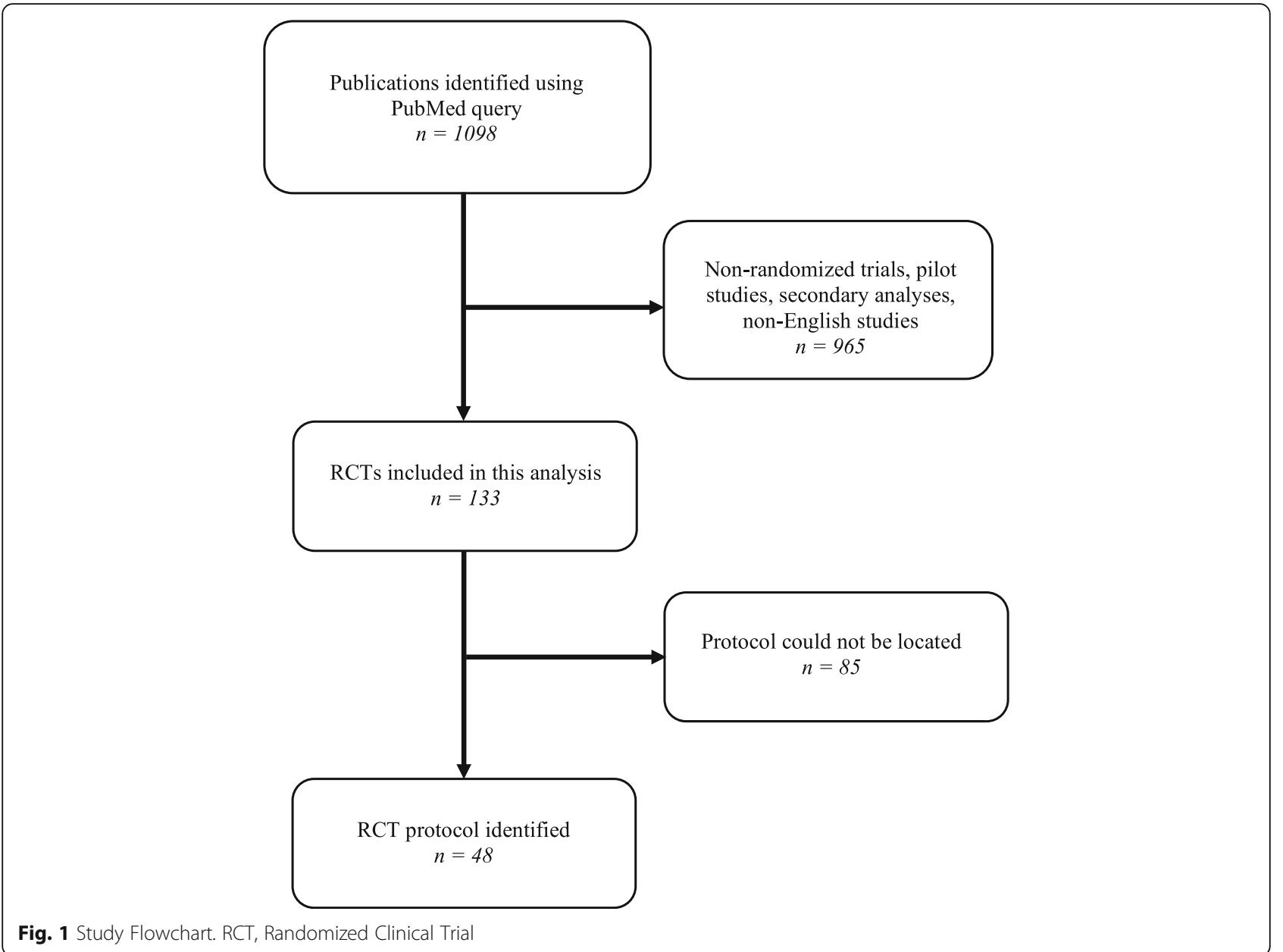

decision-making, and health literacy (Table 1). The most common primary endpoints included symptom management (29.4\%), event-free survival (21.0\%), and overall survival (9.1\%). Notably, $4.5 \%$ of RCTs did not specify a primary endpoint, which is consistent with a prior systematic review of cancer RCTs [8].

Most RCTs were supported by academic or public institutions (60.1\%), followed by industry-sponsored RCTs (24.1\%) and those without a stated funding source (15.8\%).

In total, 48 RCT protocols (36.1\%) were identified and only 24 protocols $(18.0 \%)$ were published in conjunction with the RCT manuscript. Twelve protocols $(9.0 \%)$ were previously published, 5 protocols $(3.8 \%)$ were accessible at ClinicalTrials.gov, and 7 protocols $(5.3 \%)$ were available elsewhere online. A total of 15 protocols (11.3\%) were publicly accessible without a paywall. Of the RCTs with previously published protocols, only one included a protocol update with the published results. Phase III RCTs were more likely to have an identifiable protocol compared to other RCTs (Table 1; $\mathrm{p}=0.006$ ). The median impact factor was significantly higher among journals that published protocols in conjunction with the RCT manuscript compared to journals that did not (7.0 vs $3.5 ; \mathrm{p}<0.0001)$. The median sample size among RCTs with an identifiable protocol was nearly double that of RCTs in which a protocol could not be found (203 vs 102; $\mathrm{p}=0.001$ ). Median sample sizes were similar among RCTs published in conjunction with the protocol compared to those that were not ( 312 vs 184; $\mathrm{p}=0.56$ ). There was no difference in protocol availability between industry sponsored and academic or publicly sponsored RCTs ( $43.8 \%$ vs $33.8 \%$; $\mathrm{p}=0.32$ ).

\section{Discussion}

In summary, we found only a very small number of RCTs were published along with the protocol with only one published manuscript that included a protocol update. Journals with a higher impact factor were more likely to include RCT protocols. Access to RCT protocols is critical for transparency, reproducibility, and interpretation of the study results. More journals should require publication of RCT protocols in conjunction with the study results. 
Table 1 Study characteristics for randomized cancer clinical trials

\begin{tabular}{|c|c|c|}
\hline & RCTs with protocols, $n=48$ & RCTs without protocols, $\mathrm{n}=85$ \\
\hline Sample size, median (range) & $203(7-13,195)$ & $102(6-3864)$ \\
\hline \multicolumn{3}{|l|}{ Type of cancer, n (\%) } \\
\hline Central nervous system & 0 & $3(3.5)$ \\
\hline Head and neck & $3(6.2)$ & $5(5.9)$ \\
\hline Gastrointestinal & $7(14.6)$ & $21(24.7)$ \\
\hline Lung & $6(12.5)$ & $6(7.1)$ \\
\hline Genitourinary & $11(22.9)$ & $13(15.3)$ \\
\hline Breast & $9(18.8)$ & $20(23.5)$ \\
\hline Leukemia/lymphoma & $5(10.4)$ & $6(7.1)$ \\
\hline Melanoma & $1(2.1)$ & $2(2.3)$ \\
\hline Soft tissue sarcoma & $1(2.1)$ & $1(1.2)$ \\
\hline Thyroid & 0 & $1(1.2)$ \\
\hline Multiple & $5(10.4)$ & $7(8.2)$ \\
\hline \multicolumn{3}{|l|}{ Study type, n(\%) } \\
\hline Cancer-directed therapy & $25(52.1)$ & $29(34.1)$ \\
\hline Supportive care & $17(35.4)$ & $44(51.8)$ \\
\hline Imaging & $1(2.1)$ & $2(2.4)$ \\
\hline Preventative/screening & $2(4.2)$ & $6(7.0)$ \\
\hline Surgical/anesthesia & $1(2.1)$ & $4(4.7)$ \\
\hline Other & $2(4.2)$ & 0 \\
\hline \multicolumn{3}{|l|}{ Primary endpoint ${ }^{a}, \mathrm{n}(\%)$} \\
\hline Overall survival & $4(7.4)$ & $9(10.1)$ \\
\hline Event-free survival & $15(27.8)$ & $15(16.9)$ \\
\hline Response rate & $4(7.4)$ & $6(6.7)$ \\
\hline Symptom management & $14(25.9)$ & $28(31.5)$ \\
\hline Other & $17(31.5)$ & $25(28.1)$ \\
\hline Not specified & 0 & $6(6.7)$ \\
\hline Single primary endpoint & $42(87.5)$ & $75(88.2)$ \\
\hline Co-primary endpoints & $6(12.5)$ & $4(4.7)$ \\
\hline \multicolumn{3}{|l|}{ Trial phase, n (\%) } \\
\hline III & $21(43.8)$ & $18(21.2)$ \\
\hline$\|$ & $10(20.8)$ & $26(30.6)$ \\
\hline Not specified & $17(35.4)$ & $41(48.2)$ \\
\hline \multicolumn{3}{|l|}{ Source of funding } \\
\hline Industry & $14(29.2)$ & $18(21.2)$ \\
\hline Academic/public & $27(56.2)$ & $53(62.3)$ \\
\hline None listed & $7(14.6)$ & $14(16.5)$ \\
\hline
\end{tabular}

${ }^{a}$ Co-primary endpoints were counted twice 


\section{Abbreviations}

RCT: Randomized clinical trial

\section{Supplementary Information}

The online version contains supplementary material available at https:/doi. org/10.1186/s13063-021-05382-7.

Additional file 1. PubMed Search Query. Description: This additional file contains the complete original PubMed search query used to generate the initial study cohort of 1098 results, which were then reviewed to identify randomized clinical trials.

Additional file 2. Journal and Protocol Availability Status for All Included Trials. Description: This additional file contains the PubMed ID, journal and protocol availability status for all 133 studies included in this analysis.

\section{Acknowledgements}

Not applicable

\section{Authors' contributions}

$C B$ and $K Z$ designed the initial search query and reviewed the results. $C B$ and $K Z$ performed the statistical analyses. $C B, L M, N L$, and $K Z$ contributed to the data interpretation and writing of the manuscript. All authors read and approved the final manuscript.

\section{Funding}

The authors have no financial conflicts of interest or disclosures related to this work and did not receive any external or third-party funding.

\section{Availability of data and materials}

The datasets used and analyzed during the current study are available from the corresponding author on reasonable request. Additional file 1 contains the complete PubMed search query used to generate the initial study dataset. Additional file 2 contains the PubMed ID, journal, and protocol availability for the included randomized clinical trials.

\section{Declarations}

Ethics approval and consent to participate

Not applicable

\section{Consent for publication}

Not applicable

\section{Competing interests}

The authors declare that they have no competing interests.

\section{Author details}

${ }^{1}$ Weill Cornell Medical College, New York, NY, USA. ${ }^{2}$ Department of Radiation Medicine and Applied Sciences, University of California San Diego, La Jolla, CA, USA. ${ }^{3}$ Department of Radiation Oncology, Memorial Sloan Kettering Cancer Center, New York, NY, USA

Received: 18 January 2021 Accepted: 28 May 2021

Published online: 27 June 2021

\section{References}

1. Chan A, Hróbjartsson A, Haahr MT, Gøtzsche PC, Altman DG. Empirical evidence for selective reporting of outcomes in randomized trials: Comparison of protocols to published articles. JAMA. 2004;291:20.

2. Boutron I, Dutton S, Ravaud P, Altman DG. Reporting and interpretation of randomized controlled trials with statistically nonsignificant results for primary outcomes. JAMA. 2010:303:20

3. Lucey M, Clark J, Glasziou P. Public availability of trial protocols. Lancet 2017;390:10113.

4. Zakeri K, Noticewala S, Vitzthum L, Sojourner E, Shen H, Mell L. 'Optimism bias' in contemporary national clinical trial network phase III trials: Are we improving? Ann Oncol. 2018;29:10.
5. Altman DG, Furberg CD, Grimshaw JM, Rothwell PM. Lead editorial: Trials using the opportunities of electronic publishing to improve the reporting of randomised trials. Trials. 2006;7(1):6. https://doi.org/10.1186/1745-6215-7-6.

6. Raghav KP, Mahajan S, Yao JC, Hobbs BP, Berry DA, Pentz RD, et al. From protocols to publications: A study in selective reporting of outcomes in randomized trials in oncology. J Clin Oncol. 2015;33:31.

7. Spence O, Hong K, Onwuchekwa Uba R, Doshi P. Availability of study protocols for randomized trials published in high-impact medical journals: A cross-sectional analysis. Clin Trials. 2020;17(1):99-105. https://doi.org/10.11 77/1740774519868310.

8. Mell LK, Lau SK, Rose BS, Jeong JH. Reporting of cause-specific treatment effects in cancer clinical trials with competing risks: A systematic review. Contemp Clin Trials. 2012;33:5.

\section{Publisher's Note}

Springer Nature remains neutral with regard to jurisdictional claims in published maps and institutional affiliations.
Ready to submit your research? Choose BMC and benefit from:

- fast, convenient online submission

- thorough peer review by experienced researchers in your field

- rapid publication on acceptance

- support for research data, including large and complex data types

- gold Open Access which fosters wider collaboration and increased citations

- maximum visibility for your research: over $100 \mathrm{M}$ website views per year

At BMC, research is always in progress.

Learn more biomedcentral.com/submissions 